fixed in Douglas's pouch by dense adhesiuns at the back of the brosd ligaments, external to the nterus. As the finger was paissed into Dongles's pouch it entered on each side a sac lying pnder the ovary, into which the peritoneal surface of the ovary projed project ovaries they appea sign broad ligaments were othen being well marked.

I then proceeded as in the former case, of which the diagrams should be examined. Mr. Doran passed a uterine sound upon the point of which I cut down and laid open the uterine cavity. Then a drainage tube was passed downwards to reach from the upper end of the uterine cavity to the vaginal orifice. Next the ovaries and sacs were flxed over the uterine cavity, and all were covered in by an omental graft.

Progress.-Unfortunately the patient had been rendered very weak by the recurring attacks of peritonitis. As I began to separate the adhesions she became faint, and the anaesthetist Dr. Bourns had to start saline infusions, which were continned for several days. Her condition made me hurry, and I suppose clot escaped by the vagina and a little by the abdominal wound for some days.

Result.

Apart from this incident the patient made a good recovery. A month after the last attack of pain, when another could otherwise have been anticipated, the patient felt no distarbance whatever. This relief cheered her up, and she notably improved in colour. and put on weight. She went home, and is now quite well.

Since the operation the date for an attack has three times elapsed without the patient being in any way troubled. She thus resembles the first case, who has been again seen more than a year and a half after the operation, and has no feelings whatever relating to menstruation.

\section{CASE OF PROLAPSE OF THE INVERTED UTERUS DURING LABOUR.}

ALFRED S. HENDRIE, M.B., Ch.B.EdIN., LOWESTOFT.

INVERSION and prolapse of the uterus during labour being a rare occurrence, the following notes of a case may be of interest. The patient was a married woman, aged 24, to whose second confinement I was called on November 6 th 1910 , at 1.30 a.m.

Previous History.

The first labour had occurred two years and nine month previously, and was natural except that the placenta was adherent. She had never at any time had any gynaecological symptoms, and had always been strong and healthy. The second child was born about half an hour before I arrived. Labour began at 5 a.m. on November 5 th. The pains increased in severity at 5 p.m., but there was a long interval between them.

State on Examination.

On entering the room I found the midwife attempting to deliver what she called a "false conception." A mass, with the placenta adherent, was protruding from the vulva, and, on closer examination, the case was found to be one of inverted uterus with complete prolapse, the whole organ appearing uterus with complete prolapse, the whole organ appearing
outside the valva. The placenta was rapidly stripped off, there outside the vulva. The placenta
boing absolutely no haemorrhage.

\section{Treatment.}

The uterus was returned to the vagina, no attempt being made to correot the deformity at the moment owing to the extremely critical condition of the patient. The entire absence of haemorrhage was considered a further justification for temporizing. Active stimulation was resorted to, strychnine and digitalin being administered hypodermically and friction to the extremities, pending the arrival of assistance.

Dr. Tyson soon arrived, and restored the uterus to its normal condition withont much difficulty. The administration of an ansesthetio was considered insdvigable owing to the collapsed anesthetion owing to the collapsed A hot intrauterine douche of 1 per cent. lysol was given, and two pints of normal saline solution were introduced into the rectum ; rô grain ergotin citrate was given hypodermically.

$$
\text { Progress. } 3:
$$

Daring the night the patient felt stiff and cold, and did not sleep. The temperature varied between $100^{\circ}$ and $102^{\circ}$ for about week. It fell to normal on November 13 th. There was a slíght rise for about three days, but on. November 16th the temperature was again normal, and has remained so ever since. Quinine, strychnine and iron were given from the outset, and on November 9 th $10 \mathrm{c.cm}$. antistreptococcic polyvalent serum were injected under the skin of the abdomen. As the pulse-rate was inclined to be rapid, strophanthus was now added to the mixtare with very beneficial results. The bowels acted naturally on the second day and were afterwards regulated by sulphate of magnesia.

Result.

The patient was kept in bed for a month, on a couch for a urther week, and was then allowed to go downstairs. She now feels perfectly well. Menstruation occurred on December 17th, this corresponding to the time expected.

\section{REMARKS.}

There is some difference of opinion as to how to deal with the placenta if it be still attached to the uterus.

Galabin ${ }^{1}$ says :

If the placenta. is still attached, it should be peeled off first, because the size of the mass to be returned is by that means considerably reduced.

According to Whitridge Williams ${ }^{2}$ :

If the placenta is still attached to the uterus, it is generelly dvisable to defer its separation until reposition has. been effected, because, the contractile function of the inverted uterus being in abeyance, there is always the risk of profuse haemorrhage.

Herman ${ }^{8}$ states that :

If the placenta is still attached to the uterus it matters little whether you detach it or not. If you can peel it off quickly, do so; if not, reduce the inversion with the placenta attached.

In this particular case, the prompt removal of the placenta greatly facilitated further manipulations.

Referring to the frequency of the condition Williams says:

According to Beckmann, not a single case occurred in 250,000 labours in the St. Petersburg Lying-in Hospital, while Madden noted it once in 190,833 deliveries in Dublin.

I am greatly indebted to Dr. Wilson Tyson for his very valuable help and suggestions, and for permission to publish the case.

REFERENCES.

1 Galabin, Manual of Midwifery, 1897, p. 741. ${ }^{2}$ Williams, Obstetrics, 1908, p. 825. ${ }^{3}$ Herman, Difficult Labour, 1895, p. $342 .{ }^{4}$ Williams, Obstetrics, 1908, p. 823.

\section{THE TREATMENT OF RECTAL CANCER.:}

BY

HARRISON CRIPPS, F.R.C.S.,

CONSULTING SURGEON, ST. BARTHOLOMEW'S HOSPITAL.

The subject under consideration is one to the study of which I have devoted a large part of my professional life, so it will be difficalt for me to condense my remarks within the proper time limit. It is now over thirty years since I was awarded the Jacksonian Prize for the subject and between that time and the present $I$ have had under observation over 1,000 cases.

At first sight the pathology of rectal cancer may appear to be of secondary importance, seeing the precise subject of discussion is treatment; bat a right knowledge of the pathology of the disease is really the secret of its successful treatment.

With the exception of two or three cases of melanotic cancer and two or three cases of sarcoma out of the large number of cases of rectal cancer I have seen, the whole of the remainder heve been adenoid cancer; by this I mean a proliferation or overgrowth of epithelium of Lieberkuhn's follicles and the reproduction of those follicles on a large scale. There are two ways in which these growths appear from Lieberknhn's follicles: one, when they commence on the summit of some of the folds of the rectum, and the other where they appear to commence at the base. It is the same disease but in a different situation.

Nevertheless there is a vast clinical difference. When the growth appears on the surface of the fold it has a free space to grow in, and grows like a tree in the free space of the rectal passage. What becomes of it? It grows with a pedicle or trunk; it becomes a polypus; it never grows to excess in size; it is not malignant, in that it does not affect the glands or general organs, and if removed properly at the base it seldom recurs.

Adenoid cancer is the same growth turned upside down. If instead of growing free towards the surface it grow.s

* A contribution to the discussion on this subject at the Royal Societs of Medicine of January $10 \mathrm{th}$, see p. 200. 